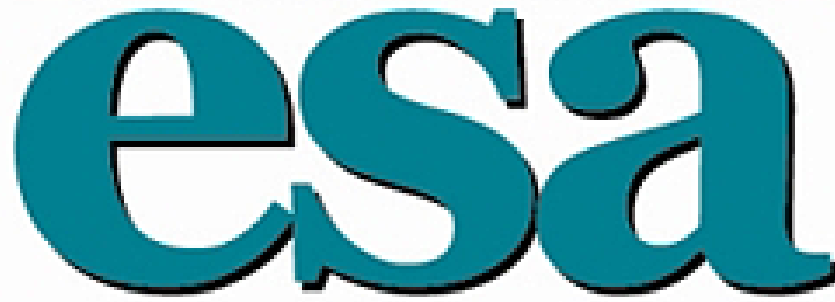

Wildland recreation disturbance: broad-scale spatial analysis and management Author(s): Kevin J Gutzwiller, Ashley L D'Antonio and Christopher A Monz

Source: Frontiers in Ecology and the Environment, November 2017, Vol. 15, No. 9 (November 2017), pp. 517-524

Published by: Wiley on behalf of the Ecological Society of America

Stable URL: https://www.jstor.org/stable/44989407

JSTOR is a not-for-profit service that helps scholars, researchers, and students discover, use, and build upon a wide range of content in a trusted digital archive. We use information technology and tools to increase productivity and facilitate new forms of scholarship. For more information about JSTOR, please contact support@jstor.org.

Your use of the JSTOR archive indicates your acceptance of the Terms \& Conditions of Use, available at https://about.jstor.org/terms 


\title{
Wildland recreation disturbance: broad-scale spatial analysis and management
}

\author{
Kevin J Gutzwiller ${ }^{1 *}$, Ashley L D'Antonio ${ }^{2}$, and Christopher A Monz ${ }^{3}$
}

Wildland recreation that does not involve animal harvests (non-consumptive recreation) often influences various components of natural systems, including soils, water, air, soundscapes, vegetation, and wildlife. The effects of non-consumptive recreation on wildlife have typically been assessed at spatial scales that are not only much smaller than the overall distributions of this disturbance but also much smaller than the areas that species use during a season or year. This disparity in scales has prevented effective assessment and management of broad-scale recreation disturbance for many species, especially wildlife. We applied three software systems (ArcGIS, FRAGSTATS, and Conefor) to demonstrate how metrics commonly measured by landscape ecologists can be used to quantify broad-scale patterns of non-consumptive recreation. Analysts can employ such metrics to develop predictive models of how recreation disturbance - by itself and in additive or interactive combinations with other landscape characteristics - may affect wildlife responses across large areas. In turn, these models can inform decision making in broad-scale recreation management.

Front Ecol Environ 2017; 15(9): 517-524, doi: 10.1002/fee.1631

W ldland recreation and nature-based tourism activities such as hiking, mountain biking, horseback riding, the viewing of wildlife, and camping comprise much of the direct human use of parks and other protected areas. These non-consumptive (non-harvest) types of recreation often induce some degree of ecological change, and minimizing degradation while allowing visitation is a common management concern in protected areas worldwide. A large body of research on the relationships between recreation and tourism activities and ecological change forms the basis for the discipline of recreation ecology. Recent analyses (eg Cole 2004; Monz et al. 2010; Hammitt et al. 2015), and a review in this journal (Monz et al. 2013), indicate important responses

\section{In a nutshell:}

-Wildland recreation activities can disturb wildlife across large expanses of land, but most of the research on this issue has been conducted in relatively small areas

- The disparity between the scale of recreation disturbance and disturbance-associated research hinders effective disturbance assessment and management

- Recreation ecologists and managers can quantify disturbance across large areas by using landscape-ecological metrics that are obtainable from geographic information systems and associated statistical approaches

- These metrics are suitable for developing predictive models that can provide insights into how wildland recreation disturbance should be managed across landscapes

${ }^{1}$ Department of Biology, Baylor University, Waco, TX * (kevin gutzwiller@baylor.edu); ${ }^{2}$ Department of Forest Ecosystems and Society, Oregon State University, Corvallis, OR; ${ }^{3}$ Department of Environment and Society, The Ecology Center, Utah State University, Logan, UT to recreation disturbance that are species-, ecosystem-, use level-, and type-dependent.

Wildland recreation disturbance has the potential to generate a variety of ecological consequences. For example, the effects of both acute and chronic trampling of various types of vegetation range from short-term loss of plant cover to more enduring changes in species composition. Recreation activities have also been shown to increase soil erosion and affect other ecosystem properties via direct effects of air and water pollution, noise, wildlife disturbance, and associated feedbacks (Hammitt et al. 2015). Understanding relationships between recreation attributes (eg timing, intensity, duration, and location) and consequent ecosystem responses is essential for developing sustainable management solutions. The sources cited above provide the reader with the most comprehensive review of recreation ecology to date.

One of the most challenging and pressing aspects of recreation ecology is to understand the effects of nonconsumptive recreation on wildlife. These effects have not been investigated extensively enough to enable management-level generalizations (Monz et al. 2010; Hammitt et al. 2015). However, it is well established that non-consumptive recreation can cause a range of important disturbances for wildlife such as energetic and physiological stresses (Bélanger and Bédard 1990), temporal or spatial displacement from preferred environments (Anthony et al. 1995; Newsome et al. 2005; Reed and Merenlender 2008), reductions in reproduction rates and population levels (Burger 1995), and alterations in species composition and diversity (Gutzwiller 1995). If not properly managed, human-wildlife interactions may also result in detrimental wildlife behavior such as food attraction and dependencies on human food sources (Larson 1995; Orams 2002). 

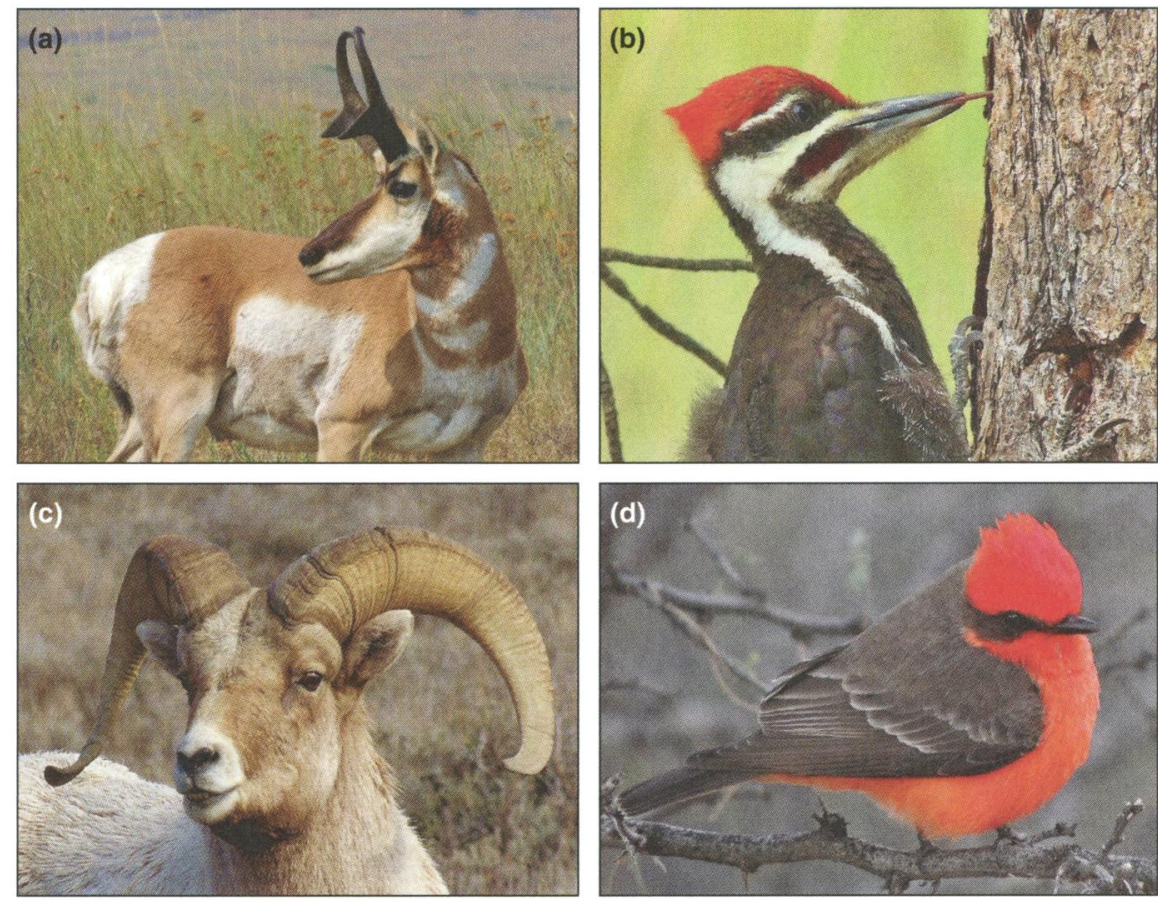

Figure 1. Examples of bird and mammal images often sought by visitors to parks and other wildlands: (a) pronghorn (Antilocapra americana), (b) pileated woodpecker (Dryocopus pileatus), (c) bighorn sheep (Ovis canadensis), and (d) vermillion flycatcher (Pyrocephalus rubinus). Maintaining the potential for wildlife photography while minimizing the chance for associated negative impacts requires knowledge of landscape-scale recreation disturbance.

Even seemingly innocuous activities such as wildlife photography have the potential to disturb organisms if enthusiasts are not cautious. Wildlife photography has long been a common activity in many protected areas. Colorful birds and larger mammals (Figure 1) are often among the more popular subjects. Close and repeated approaches, chasing, groups of photographers, or other circumstances that alert or alarm individuals may displace wildlife from food or shelter, increase their avoidance behavior and hence energy expenditure, promote detection by predators, and disrupt parental care (Gutzwiller et al. 2002; Bateman and Fleming 2017).

Most of the research on recreation ecology in general, and on non-consumptive recreation specifically, has been carried out at individual sites or in areas that are small relative to the size of protected areas (Monz et al. 2010; Hammitt et al. 2015). Few studies have considered landscape-scale effects (Buckley 2013), which are likely to be important to wildlife because many species are influenced by conditions at multiple spatial extents (Gutzwiller 2002), and because many species' home ranges and populations span large areas. Efforts to scale up existing studies to a landscape scale are fraught with conceptual and practical problems, not the least of which is a lack of understanding of the actual spatial patterns of recreation use and associated disturbance potential. Because recreation activity is not uniformly distributed across wildlands, disturbance patterns at small extents may not be representa-
Here, we illustrate an approach for characterizing recreation disturbance at broad spatial scales. A review of previous work revealed several related research themes, which informed our study. For instance, a limited number of studies have used a geographic information system (GIS) to examine recreation use or impacts at the scale of protected areas (eg Arrowsmith and Inbakaran 2002; Hawes et al. 2013; Tomczyk and Ewertowski 2016). These studies have generally focused on vegetation disturbance, soil loss, and trail impacts. Three studies (Leung et al. 2011; Wimpey and Marion 2011; Barros and Pickering 2017) used ArcGIS software (ESRI 2016) to compute landscape-ecological indices of fragmentation to describe the impact of informal (visitor-created) trails on patches of natural areas within parks. This literature provided a basis for our study, but we extend this work in three fundamental ways. First, our analysis includes the actual spatial pattern of recreational visitors on the landscape, not just the observable effects of recreation use (eg trail conditions). Second, we explain how landscape-ecological metrics applied to recreation disturbance can be employed with other landscape variables to build predictive wildlife response models for informing landscape-wide management of recreation disturbance. Third, in addition to demonstrating the use of ArcGIS for these purposes, we demonstrate how to apply FRAGSTATS (McGarigal et al. 2012) and Conefor (Saura and Torné 2009) software to calculate broad-scale metrics of recreation disturbance. 
Our approach involves tools and metrics that have not been used previously to model broad-scale wildlife responses to recreation disturbance. We treat recreation disturbance as a landscape attribute, just as a landscape ecologist would consider a land-cover type (eg forest) to be a landscape attribute. Our primary objectives are to show how to quantify spatial patterns of wildland recreation disturbance at landscape extents (often tens of square kilometers), and to explain how these metrics can be applied to build predictive wildlife response models that inform landscape-wide management of nonconsumptive recreation disturbance.

\section{Methodological background and approach}

\section{Measuring spatial patterns of recreation disturbance}

Although it is not appropriate to assume that all recreation activities necessarily impact wildlife, for simplicity we used the term "recreation disturbance" to describe the potential effects of recreation - specifically in this study of hikers and informal trails. However, the approaches we illustrate are appropriate for studying the effects of disturbance from many different types of wildland recreation.

We used global positioning system (GPS) tracking techniques to measure spatial patterns of recreation disturbance (see workflow in WebPanel 1) in a variety of recreation corridors (locations where wildland recreation is common) (D'Antonio et al. 2010). A random sample of hikers, surveyed over 2-4 weeks, carried GPS units during their visits to Acadia National Park (ACAD) in
Maine, Rocky Mountain National Park (ROMO) in Colorado, and Grand Teton National Park (GRTE) in Wyoming. Hikers returned the GPS units to researchers after completing their hikes, and the track data, recorded as points on the landscape, were processed in GIS software. Extensive experience with GPS visitor tracking by the authors and others suggests little evidence of behavior bias by study participants (Beeco and Hallo 2014; Kidd et al. 2015). All data points collected in a given study were combined and converted into a kernel density map (for a glossary of specialist terminology, see Panel 1) and classified into areas of low, medium, and high levels of recreation disturbance.

We also measured recreation disturbance in ROMO by mapping the location and length of informal trails (created by visitors as indicated by location, width, and boot prints) using survey-grade GPS units (D'Antonio et al. 2013). The informal trail data were uploaded to a GIS, and we created a line-density map showing areas of low, medium, and high levels of recreation disturbance.

To demonstrate how recreation disturbance can be quantified for analysis of recreation-wildlife relationships, we used ArcGIS to place four example wildlife sampling locations (labeled A, B, C, and D) within the GRTE landscape. These locations were generated randomly, and we centered 500-, 1000-, 1500-, and 2000-m-radius circular areas ("buffers" hereafter) on each example sampling location. The buffers were overlaid on the recreation disturbance map for GRTE and used to extract the different-sized circular areas from that layer for subsequent analysis.

\section{Panel 1. Glossary of selected terms in landscape ecology and geographic information systems}

Connectivity: Degree to which a landscape condition (eg a habitat type) is continuous across space (Turner et al. 200I).

Equivalent connectivity (EC): The area of a single habitat patch that would result in the same level of measured connectivity found in the landscape's habitat pattern. EC can be applied to examine changes in IIC and PC (both defined below) in relation to changes that occur in the mosaic of different habitat types. EC is also a useful measure when the landscape scale examined is relatively small (as it sometimes is when studying recreation disturbance) and would result in extremely low values of IIC and PC that could be difficult to interpret (Saura et al. 20II).

Euclidean nearest neighbor distance (ENND): Shortest distance between a patch and its nearest neighbor as measured by a straight line (McGarigal et al. 20I2). By comparing the mean of all patch ENNDs to the standard deviation, this distance can be an indicator of patch isolation and pattern across a landscape.

Integral index of connectivity (IIC): A measure of habitat availability that incorporates not only the connection between habitat patches but also the size of the available habitat patches. IIC ranges from 0 to I with increasing connectivity, and a value of I corresponds to a single patch (Saura et al. 20II).

Kernel density: The density of point or line data within a curved or circular neighborhood around a point as calculated with a particular mathematical function. This function generates a smoothed density surface (a map showing areas of different densities) that estimates the spatial patterns of a population based on the observed spatial patterns of a sample (Brunsdon 1995).

Likelihood estimation: The output from a kernel density calculation, where each cell or pixel on the landscape represents the probability of an event occurring. In this paper, the kernel density calculates the likelihood of an "event" of low, medium, or high recreation disturbance occurring in an area.These likelihood estimates can be converted to expected occurrences that can be reported as points per unit area.

Probability of connectivity (PC): Probability that two organisms, randomly placed on the landscape, will be located in habitat patches that are interconnected (Saura et al. 20II).

Spatial extent: Size of area for which a metric is computed (Turner et al. 200I).

Spatial grain: Finest resolution of data across space (cell or pixel size) (Turner et al. 200I). 


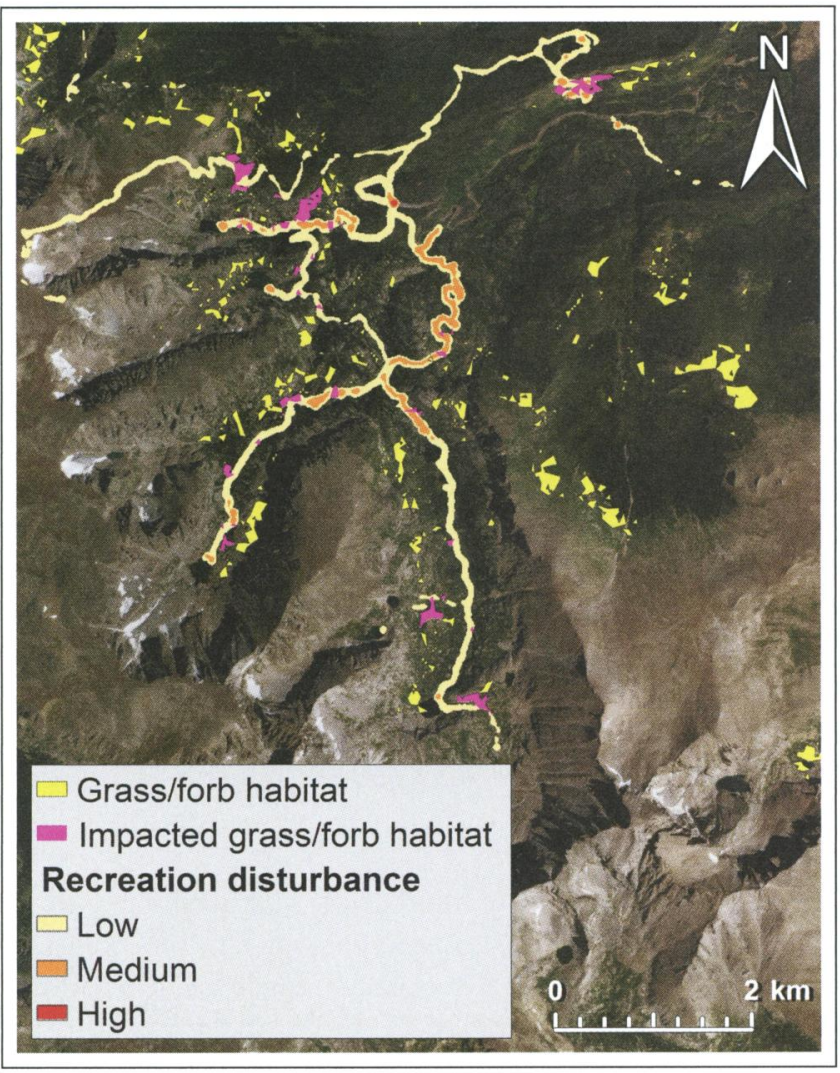

Figure 2. Recreation disturbance as measured by density of hikers in Rocky Mountain National Park (low = an estimated count of 9-17 visitor points per raster cell; medium $=18-25$ points per cell; high = 26-207 points per cell; breaks based on one SD of the dataset). Basemap sources: Esri, DigitalGlobe, GeoEye, i-cubed, USDA FSA, USGS, AEX, Getmapping, Aerogrid, IGN, IGP, swisstopo, GIS User Community, and NPS: 2009 ROMO Vegetation Inventory Project.

\section{Using landscape metrics to quantify recreation disturbance}

We examined recreation disturbance maps using three different programs commonly employed in landscape ecology: ArcGIS, FRAGSTATS, and Conefor. The metrics and means of analysis that these systems offer are diverse and highly relevant for quantifying landscapescale recreation disturbance. We encourage recreation ecologists to explore these programs for metrics that would be useful in their particular situations. For the sake of brevity, we illustrated only a few of the available metrics here.

For the analysis using ArcGIS, we converted the recreation disturbance maps from raster cells (pixels on a map) to polygons (areas with discrete edges) and calculated an area value for each level of recreation disturbance. The areal extents of the polygons for each disturbance level (low, medium, and high) were summed, and these totals were used to calculate the percentage of the landscape covered by each level of disturbance. In FRAGSTATS, for each recreation disturbance level, we calculated the number of patches as well as the mean and standard deviation (SD) of the Euclidean nearest neighbor distance (ENND; Panel 1) for the patches. Using Conefor, we examined the influence of recreation disturbance on habitat connectivity by overlaying a map of recreation disturbance in $\mathrm{ROMO}$ with a map of patches of subalpine grass and forb vegetation. We calculated the changes in habitat connectivity with the presence of recreation disturbance for two example species that had a $25 \%$ probability of dispersing and that could disperse $10 \mathrm{~km}$ (for an ungulate) or $0.25 \mathrm{~km}$ (for a small mammal). We also used Conefor to compute the percent change in equivalent connectivity (EC) values for the integral index of connectivity (IIC) and the probability of connectivity (PC) (Panel 1) (Saura et al. 2011).

\section{Results}

\section{Percentage of landscape with recreation disturbance}

Recreation disturbance occurred in a small percentage of the area of each of the recreation corridors examined (WebTable 1). All three levels of recreation disturbance combined (for hikers) covered $2.1 \%$ and $1.5 \%$ of the ROMO (Figure 2) and GRTE (Figure 3) corridors, respectively. In the ROMO corridor, recreation disturbance as measured by informal trail formation occurred in a larger percentage $(15.4 \%)$ of the landscape (Figure 4a) than did disturbance from hikers. Example sampling locations A and D in GRTE (Figure 3) had very little or no disturbance within the buffers. For sampling location B, no more than $2 \%$ of the total area (regardless of buffer size) exhibited any individual level of disturbance. Location $\mathrm{C}$ had the highest percentage of area disturbed by recreation, and most of this occurred within the 500- and 1000-m-radius buffers; high-level disturbance occurred in 7-8\% of these two buffers at location C (WebTable 1).

The recreation corridor in ACAD is a mountain summit with an alpine tundra ecosystem. Alpine summits are popular destinations in the northeastern US, but they occupy very small land areas (Figure $4 b$ ). Disturbance from recreation occurred in approximately $14.3 \%$ of this relatively small but ecologically unique and sensitive area (WebTable 1).

\section{Distribution of recreation disturbance on the landscape}

In $\mathrm{ROMO}$ (for disturbance from hikers and informal trails) and in GRTE, the ENNDs indicated that patches of the different disturbance levels tended to be irregularly distributed on the landscape (SDs were large as compared to the means) (WebTable 1). For the example sampling locations with more disturbance (locations B and C), all of the high- and medium-level patches 
occurred relatively uniformly within the buffers (SDs were small as compared to the means), whereas lowlevel patches were irregularly distributed only in the 2000-m buffers. On the mountain summit in ACAD, patches of disturbance formed a concentric pattern with a single high-level patch occurring at the summit and regular patterns of medium- and low-level patches encircling the high-level patch (Figure 4b).

\section{Impact of recreation disturbance on habitat connectivity}

Recreation disturbance occurred at 23 (pink patches in Figure 2) (4\%) of the 539 patches (yellow plus pink patches in Figure 2) of grass and forb habitat in the $\mathrm{ROMO}$ corridor. When the 23 patches that were intersected by disturbance were removed to simulate loss of wildlife access arising from visitor-induced avoidance of the patches, we observed an $11 \%$ decrease in EC (IIC) and a $12 \%$ decrease in EC (PC). These changes in connectivity were identical for the two example wildlife species (one able to disperse $10 \mathrm{~km}$ and one able to disperse $0.25 \mathrm{~km}$ ).

\section{Implications for wildlife and their habitats}

Although recreation disturbance may occur in a relatively small percentage of a landscape (as in the recreation corridors we examined), the disturbance can be quite detrimental if it occurs in vital habitat. Sensitive species whose territories or home ranges include the high-level patches in GRTE, for example, may be prevented via displacement from accessing limited and essential resources in and near those patches. In ACAD, only $6.6 \%$ of the landscape was covered by a single patch of high-level disturbance, but that patch overlapped with an ecologically sensitive part of that ecosystem, the mountain summit. Moreover, as we found for the two example species in $\mathrm{ROMO}$, recreation disturbance can reduce habitat connectivity even when the disturbance affects only $4 \%$ of habitat patches.

Knowledge about such spatial patterns can be used to protect wildlife and habitats, but its usefulness for these purposes will not be fully realized without additional analyses. In the following sections, we consider key steps for incorporating the metrics into research that develops predictive models and into management that applies those models in decision making.

\section{Modeling wildlife responses to broad-scale patterns of recreation disturbance}

\section{Spatial scale}

Spatial scale involves two components (Turner et al. 2001): extent and grain (Panel 1). Wildlife may respond differently to conditions at different spatial extents

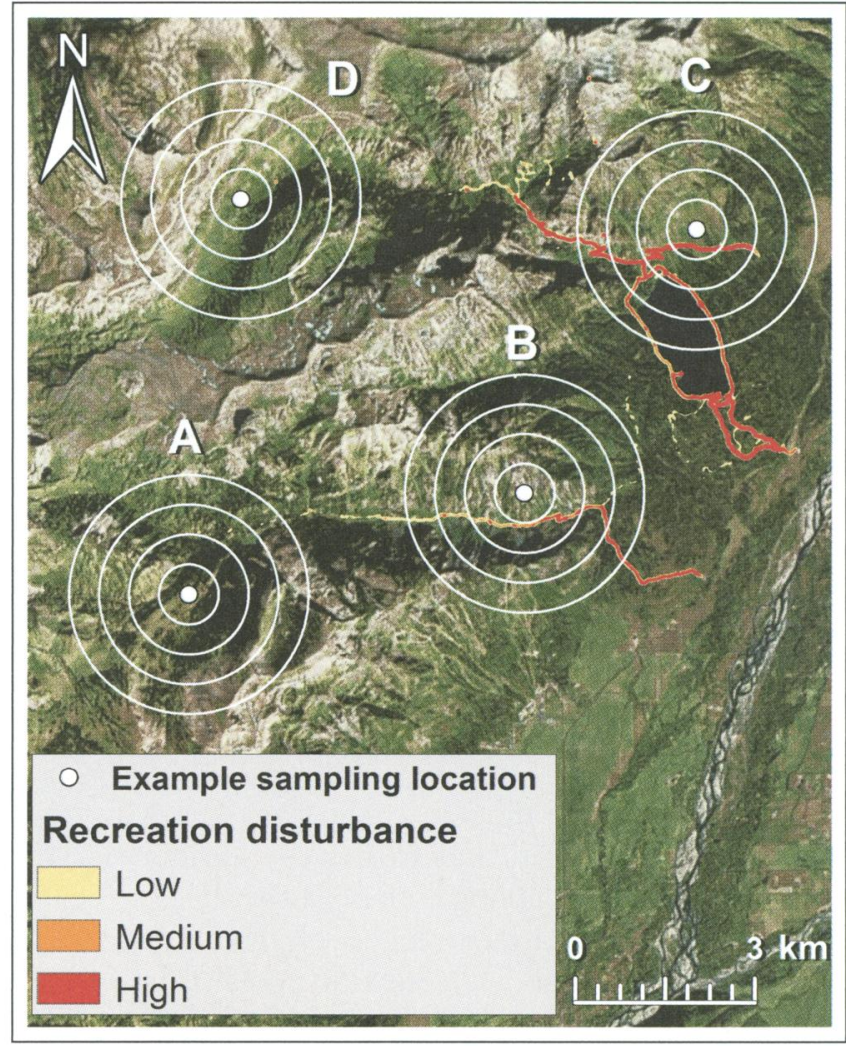

Figure 3. Recreation disturbance as measured by density of hikers in Grand Teton National Park (low = an estimated count of 3-9 visitor points per raster cell; medium $=10-16$ points per cell; high $=17-840$ points per cell; breaks based on one SD of the dataset), with example sampling locations. Basemap sources: Esri, DigitalGlobe, GeoEye, i-cubed, USDA FSA, USGS, AEX, Getmapping, Aerogrid, IGN, IGP, swisstopo, and the GIS User Community.

(Freemark et al. 2002; Gutzwiller 2002) and grains, and these responses may vary among species. Thus, an important challenge in modeling broad-scale recreationwildlife relationships is to identify the relevant spatial extent and grain for the particular organism and response variable of interest.

One method to identify the relevant spatial extent is to first obtain metrics of the spatial patterns of recreation disturbance for a range of spatial extents (see Figure 3) that may be relevant to the organism. Decisions about which extents to consider can be based on a species' dispersal ability, home range size, and habitat needs during a given season or life-history stage. The second step is to assess how well the wildlife response variable is associated with the metrics for different spatial extents. For a given landscape-scale metric of recreation disturbance, the spatial extent for which the relationship is the strongest - as measured by a correlation coefficient $(r)$ or a coefficient of partial determination $\left(r^{2}\right)$, for instance - is the extent that is considered to be the most relevant for the species (Turner et al. 2001). Another means of identifying the appropriate spatial extent is to calculate the species' dis- 


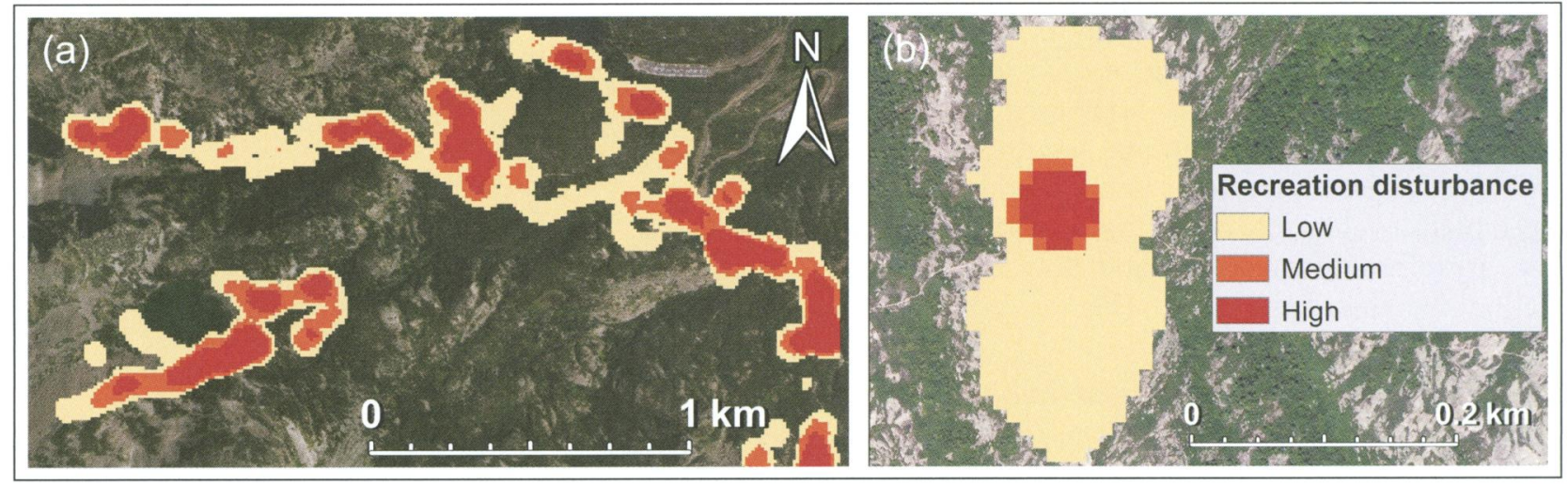

Figure 4. Recreation disturbance in (a) Rocky Mountain National Park as measured by informal trails (low $=0.011-0.023 \mathrm{~m}$ of trail per $\mathrm{m}^{2}$; medium $=0.024-0.035 \mathrm{~m}$ per $\mathrm{m}^{2}$; high $=0.036-0.21 \mathrm{~m}$ per $\mathrm{m}^{2}$; breaks based on one SD of the dataset) and (b) Acadia National Park as measured by density of hikers (low = 17-36 visitor points per raster cell; medium = 37-54 points per cell; high = 55-110 points per cell; breaks based on one SD of the dataset). Basemap sources: Esri, DigitalGlobe, GeoEye, $i$-cubed, USDA FSA, USGS, AEX, Getmapping, Aerogrid, IGN, IGP, swisstopo, and the GIS User Community.

persal distance using allometric equations involving body mass and general diet, and to use this distance as the radius of a circular sampling buffer (Gutzwiller et al. 2015).

Once the spatial extent has been chosen, one can gather information about recreation patterns within the sampling buffer centered on each site at which wildlife response data are available. A correlation-based analysis like the one outlined immediately above for spatial extent also can be applied to identify the most appropriate spatial grain. As compared to the range of possible spatial extents, there are fewer grain sizes that can be considered because grain size is limited by the resolution of available landscape data from satellites, aerial photography, and other sources.

\section{Interaction effects}

The effects of broad-scale spatial patterns of recreation disturbance on wildlife may be influenced by other broadscale conditions (Gutzwiller and Cole 2005). Because recreation impacts are often context-dependent, interactions involving recreation disturbance and other landscape variables are likely to be common. Interaction effects occur when the relationship between a response variable (eg reproduction) and an explanatory variable (eg recreation intensity in the landscape) varies with the level of the other explanatory variable involved in the interaction (eg forest connectivity in the landscape). At present, little is known about interaction effects involving recreation and other broad-scale conditions. They can be investigated with statistical models that include interaction terms involving the types of recreation metrics discussed above and other landscape variables that are relevant to wildlife populations and communities (eg percent of the landscape in different land-use types, edge density, number of habitat types, road density, and habitat connectivity). Different types of recreation and associated participant behaviors influence various wildlife species differently, and examination of variables that are directly relevant to specific focal species and recreation types will often be necessary.

Without knowledge of important interaction effects, information about broad-scale recreation impacts on wildlife will be misleading, which may result in ineffective management actions. For example, consider a scenario in which the negative effect of photographer density on a forest bird species' nest success is actually greater (more detrimental) in landscapes with less forest connectivity. Through research, recreation ecologists detect the negative association between nest success and photographer density but do not consider effects of forest connectivity and thus fail to test for an interaction effect involving photographer density and forest connectivity. They therefore do not realize that forest fragmentation (less forest connectivity) exacerbates photographer impacts. Subsequent management of photographer density based on the ecologists' research does not take into account the differences in forest connectivity in landscapes across the protected area, leading to lower nest success where there is less forest connectivity.

\section{Using recreation-wildlife models to manage recreation disturbance across landscapes}

Once models relating wildlife responses to landscape-scale recreation disturbance have been temporally and spatially validated, they can be applied in several important ways. Suppose that a researcher had a logistic regression model relating an ungulate's probability of reproduction to informal trail density (length of trail per unit area). Such a model can be used to estimate how much the probability of reproduction will change for a part of the protected area if the broad-scale trail density in that area was increased or decreased by a certain amount. The model could also be used to generate a map of the species' predicted probability of reproduction in other 
comparable protected areas for which trail density was measured. The trail density data for each spatial unit (grid cell or pixel) in the new area of interest are the input data for the model. Multiplication of the new values of trail density by the model's regression coefficient for trail density, and addition of the regression intercept, will yield a predicted value for the probability of reproduction within each spatial unit in the new area. These values can then be mapped in a GIS to show how the predicted probability of reproduction varies with trail density across the protected area's landscapes.

Of course, models may contain multiple recreation disturbance metrics, other landscape variables (eg percent forest, road density), and interactions between those variables. In this situation, it is possible to predict cumulative effects and interaction (synergistic or antagonistic) effects of these broad-scale variables on a wildlife response variable. The same basic regression calculations described above can be applied to obtain predictions of cumulative and interaction effects. Cumulative effects (combined impacts over time or space) may be important if, for instance, the densities of different types of recreationists (eg mountain bikers, campers, and horseback riders) influence predator use of sites more than does the density of any one of these types of recreationists alone. Predictive modeling involving an interaction is possible if, for example, the distance at which wildlife viewers influence raptor nest success varied substantially with the seasonal timing (Julian date) of viewing. To make predictions about the interaction effect on nest success in another area, practitioners will first require values of the crossproducts (viewing distance $\times$ Julian date) and associated main effects (viewing distance, Julian date) for each of the spatial units of interest in the new area. These values are the input data for the fitted predictive model containing the interaction, and the model will yield predicted values of raptor nest success.

All of these models can help researchers to explore the potential consequences of various management actions and thereby inform landscape-scale and park-wide decisions about how to manage recreation disturbance. For instance, let us return to the scenario in which trail density affected ungulate reproduction. To predict the probability of reproduction at a level of trail density that is consistent with a management objective, managers can input a chosen value of trail density into the fitted model. The difference between the original and new predicted probabilities will quantify the change in probability of reproduction at a given location as a consequence of the management action. For the scenario involving the interaction effect of viewing distance and Julian date, different values for viewing distance and Julian date along with their cross-product values can be obtained and used as input into the fitted model to generate predicted values of nest success. By comparing a series of such predictions to an appropriate nest success rate, managers can identify combinations of distances and dates that will be conducive to desirable raptor nest success. Another important circumstance in which recreation-wildlife models can inform management is when recreation disturbance within more than one spatial extent influences wildlife. In this situation, the types of change assessment and predictive mapping mentioned immediately above may be warranted at multiple spatial extents.

\section{Conclusions}

The approach we have presented has considerable promise for helping recreation ecologists advance understanding of the effects of broad-scale patterns of non-consumptive recreation disturbance on wildlife. It can be applied to a wide range of wildland recreation variables and for different spatial extents and grains. Spatial patterns of recreation disturbance can be used in modeling with other landscape characteristics to develop an integrated understanding of how these various landscape conditions operate simultaneously to affect wildlife responses. Considering the diverse environmental influences that wildland recreation can have (Hammitt et al. 2015), landscape-scale metrics of recreation disturbance will also be valuable for studying broad-scale recreation effects on other important components of ecological systems such as soils, water, air, soundscapes, and vegetation. Landscape analysis software can provide broadscale metrics of recreation disturbance that managers can manipulate, if necessary, through broad-scale management actions or apply in a predictive capacity when planning for future recreation uses of an area. Such metrics will supply needed advancements for reducing disturbance to wildlife and providing the many personal and societal benefits of wildland recreation.

\section{Acknowledgements}

We thank our many field assistants and graduate students, including A Kidd, K Goonan, and A Weiler, who helped to collect the field data for this analysis. Funding was provided by the US National Park Service through agreements H1200040001 and P13AC000314 under the auspices of the Rocky Mountain Cooperative Ecosystems Studies Unit. CAM also thanks the Utah State Agricultural Experiment Station for grant UTA-1084.

\section{References}

Anthony RG, Steidl RJ, and McGarigal K. 1995. Recreation and bald eagles in the Pacific Northwest. In: Knight RL and Gutzwiller KJ (Eds). Wildlife and recreationists: coexistence through management and research. Washington, DC: Island Press.

Arrowsmith C and Inbakaran R. 2002. Estimating environmental resiliency for the Grampians National Park, Victoria, Australia: a quantitative approach. Tour Manage 23: 295-309.

Barros A and Pickering CM. 2017. How networks of informal trails cause landscape level damage to vegetation. Environ Manage 60: $57-68$. 
Bateman PW and Fleming PA. 2017. Are negative effects of tourist activities on wildlife over-reported? A review of assessment methods and empirical results. Biol Conserv 211: 10-19.

Beeco JA and Hallo JC. 2014. GPS tracking of visitor use: factors influencing visitor spatial behavior on a complex trail system. J Park Recr Admin 32: 43-61.

Bélanger L and Bédard J. 1990. Energetic cost of man-induced disturbance to staging snow geese. J Wildl Manage 54: 36-41.

Brunsdon C. 1995. Estimating probability surfaces for geographical point data: an adaptive kernel algorithm. Comput Geosci 21: 877-94.

Buckley R. 2013. Next steps in recreation ecology. Front Ecol Environ 11: 399

Burger J. 1995. Beach recreation and nesting birds. In: Knight RL and Gutzwiller KJ (Eds). Wildlife and recreationists: coexistence through management and research. Washington, DC: Island Press.

Cole DN. 2004. Impacts of hiking and camping on soils and vegetation: a review. In: Buckley R (Ed). Environmental impacts of ecotourism. Wallingford, UK: Centre for Agriculture and Biosciences International.

D'Antonio A, Monz C, Lawson S, et al. 2010. GPS-based measurements of backcountry visitors in parks and protected areas: examples of methods and applications from three case studies. J Park Recr Admin 28: 42-60.

D'Antonio A, Monz C, Newman P, et al. 2013. Enhancing the utility of visitor impact assessment in parks and protected areas: a combined social-ecological approach. J Environ Manage 124: 72-81.

ESRI (Environmental Systems Research Institute). 2016. ArcGIS desktop: release 10.3. Redlands, CA: ESRI.

Freemark K, Bert D, and Villard M-A. 2002. Patch-, landscape-, and regional-scale effects on biota. In: Gutzwiller KJ (Ed). Applying landscape ecology in biological conservation. New York, NY: Springer-Verlag.

Gutzwiller KJ. 1995. Recreational disturbance and wildlife communities. In: Knight RL and Gutzwiller KJ (Eds). Wildlife and recreationists: coexistence through management and research. Washington, DC: Island Press.

Gutzwiller KJ (Ed). 2002. Applying landscape ecology in biological conservation. New York, NY: Springer-Verlag.

Gutzwiller KJ and Cole DN. 2005. Assessment and management of wildland recreational disturbance. In: Braun CE (Ed). Techniques for wildlife investigations and management (6th edn). Bethesda, MD: The Wildlife Society.

Gutzwiller KJ, Riffell SK, and Anderson SH. 2002. Repeated human intrusion and the potential for nest predation by gray jays. J Wildl Manage 66: 372-80.

Gutzwiller KJ, Riffell SK, and Flather CH. 2015. Avian abundance thresholds, human-altered landscapes, and the challenge of assemblage-level conservation. Landsc Ecol 30: 2095-110.

Hammitt WE, Cole DN, and Monz CA. 2015. Wildland recreation: ecology and management (3rd edn). Chichester, UK: John Wiley.

Hawes M, Dixon G, and Ling R. 2013. A GIS-based methodology for predicting walking track stability. J Environ Manage 115: 295-99.

Kidd AM, Monz C, D'Antonio A, et al. 2015. The effect of minimum impact education on visitor spatial behavior in parks and protected areas: an experimental investigation using GPSbased tracking. J Environ Manage 162: 53-62.

Larson RA. 1995. Balancing wildlife viewing with wildlife impacts: a case study. In: Knight RL and Gutzwiller KJ (Eds). Wildlife and recreationists: coexistence through management and research. Washington, DC: Island Press.

Leung Y-F, Newburger T, Jones M, et al. 2011. Developing a monitoring protocol for visitor-created informal trails in Yosemite National Park, USA. Environ Manage 47: 93-106.

McGarigal K, Cushman SA, and Ene E. 2012. FRAGSTATS v4: spatial pattern analysis program for categorical and continuous maps. Computer software program produced by the authors at the University of Massachusetts, Amherst. www.umass.edu/ landeco/research/fragstats/fragstats.html. Viewed 26 Oct 2016.

Monz CA, Cole DN, Leung Y-F, et al. 2010. Sustaining visitor use in protected areas: future opportunities in recreation ecology research based on the USA experience. Environ Manage 45: 551-62.

Monz CA, Pickering CM, and Hadwen WL. 2013. Recent advances in recreation ecology and the implications of different relationships between recreation use and ecological impacts. Front Ecol Environ 11: 441-46.

National Park Service. 2016. Visitor use statistics. https://irma.nps. gov/Stats. Viewed 8 Sep 2016

Newsome D, Dowling RK, and Moore SA. 2005. Wildlife tourism (volume 24). Bristol, UK: Channel View Publications.

Orams MB. 2002. Feeding wildlife as a tourism attraction: a review of issues and impacts. Tour Manage 23: 281-93.

Reed SE and Merenlender AM. 2008. Quiet, nonconsumptive recreation reduces protected area effectiveness. Conserv Lett 1 : $146-54$.

Saura S and Torné J. 2009. Conefor Sensinode 2.2: a software package for quantifying the importance of habitat patches for landscape connectivity. Environ Model Softw 24: 135-39.

Saura S, Estreguil C, Mouton C, et al. 2011. Network analysis to assess landscape connectivity trends: application to European forests (1990-2000). Ecol Indic 11: 407-16.

Smith D, Stahler D, Stahler E, et al. 2015. Yellowstone National Park wolf project annual report 2014. Yellowstone National Park, Wyoming: National Park Service, Yellowstone Center for Resources. YCR-2015-02.

Tomczyk AM and Ewertowski MW. 2016. Recreational trails in the Poprad Landscape Park, Poland: the spatial pattern of trail impacts and use-related, environmental, and managerial factors. J Maps 12: 1227-35.

Turner MG, Gardner RH, and O'Neill RV. 2001. Landscape ecology in theory and practice: pattern and process. New York, NY: Springer-Verlag.

Wimpey J and Marion JL. 2011. A spatial exploration of informal trail networks within Great Falls Park, VA. J Environ Manage 92: 1012-22.

\section{Supporting Information}

Additional, web-only material may be found in the online version of this article at http://onlinelibrary. wiley.com/doi/10.1002/fee.1631/suppinfo 